\title{
SARS-CoV-2 Virus Manifestations in the Gastrointestinal Tract: Therapeutic Implications
}

\author{
André Jefremow ${ }^{a, b} \quad$ Markus F. Neurath ${ }^{a, b}$ \\ ${ }^{a}$ Department of Internal Medicine 1, Friedrich-Alexander-Universität Erlangen-Nürnberg (FAU), Erlangen, Germany; \\ ${ }^{\mathrm{b}}$ Deutsches Zentrum Immuntherapie (DZI), Erlangen, Germany
}

\section{Keywords}

Corona $\cdot$ COVID-19 - Gastrointestinal disorders · Crohn's disease - Ulcerative colitis - Inflammatory bowel diseases . Liver damage $\cdot$ Acute pancreatitis · SARS-CoV-2

\begin{abstract}
Background: About 1 year ago a novel virus - SARS-CoV-2 began to spread around the world. It can lead to the disease COVID-19, which has caused more than 1 million deaths already. Summary: While it was first recognized as a disease leading to pneumonia and lung failure, we know by now that COVID-19 is more complex. COVID-19 is a systemic hyperinflammatory disease affecting not only the lungs, but also many other organs. Especially the gastrointestinal (GI) tract is often involved in COVID-19. Key Messages: This review provides an overview of the different affected organs of the GI tract and offers information on how gastroenterologists should take care of their patients with different GI disorders.
\end{abstract}

(c) 2020 S. Karger AG, Basel

\section{Introduction}

A new virus called SARS-CoV-2, leading to COVID-19, became a pandemic 1 year ago [1]. All over the world people became infected and many patients have died [2]. The pandemic has pushed health systems and their resources to their limits. Currently, we are experiencing the "second wave" and the number of infections is increasing dramatically. However, we have learned much during the last year. The virus uses the angiotensin-converting enzyme 2 receptor (ACE2 receptor) for entry into cells and requires the cellular serine transmembrane protease serine 2 (TMPRSS2) for priming the surface spike glycoprotein (S protein) on the surface of the virus to bind to the receptor $[3,4]$. In severe cases hyperinflammation is an essential trigger [5]. Trials using remdesivir [6, 7] and dexamethasone [8] are being conducted in COVID-19 patients who need oxygen supplementation.

We know more about the virus, the disease, and the inflammation processes, even though there are many open questions. While COVID-19 was first regarded as a type of viral pneumonia, we know today, it is in fact a systemic inflammatory disease affecting different parts of the body. For example, Leppkes et al. [9] showed an increased neutrophil activation in COVID-19 resulting in neutrophil extracellular traps and vascular damage. This review deals with the impact of COVID-19 on the gastrointestinal (GI) tract and GI diseases, taking into account patients who may have a higher risk of developing COVID-19.

\section{Prevalence of GI Symptoms in Patients with COVID-19}

GI symptoms are common in patients with COVID-19. In a multicenter study with 318 patients, Redd et al. [10] showed that $61.3 \%$ of COVID-19 patients suffered 


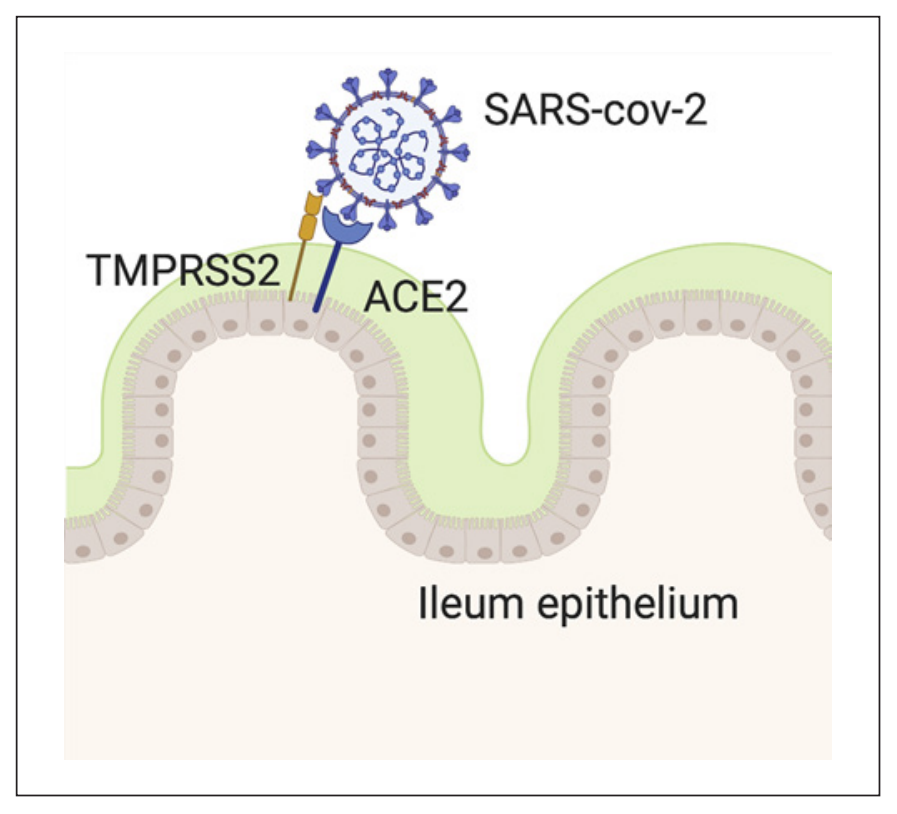

Fig. 1. The S spike of SARS-CoV-2 is activated through proteolytic cleavage by TRMPSS2 and can connect with ACE2 on the enterocyte surface. Created with Biorender.com.

from at least one GI symptom. The most common GI symptoms were loss of appetite (34.8\%), diarrhea (33.7\%), nausea (26.4), vomiting (15.4\%), and abdominal pain (14.5\%). Furthermore, 9.4\% complained about weight loss, and $0.94 \%$ about constipation. Strikingly, GI symptoms led $14.2 \%$ of the patients to seek medical help, and they were the leading symptoms in $20.3 \%$ of the patients [11].

Pan et al. [12] showed similar results in a Chinese multi-center trial that investigated 204 patients. Of these patients, GI symptoms were the only symptoms in $6 \mathrm{pa}-$ tients. Beyond that, patients with GI symptoms had higher liver enzymes, a lower monocyte count, and a longer prothrombin time. The timeframe from the beginning of the symptoms until hospital admissions was longer in patients with GI symptoms ( 9 days) than in patients without them (7.3 days). Even though not a classical GI symptom, it is worth mentioning that $8 \%$ of the patients reported a loss of smell and taste [13].

There seems to be a fecal-oral route for SARS-CoV-2, even though it is unproven [14]. It is also imaginable that SARS-CoV-2 enters the gut when the patient swallows their sputum. SARS-CoV-2 can be detected in the feces $2-5$ days after it is found in the respiratory tract. Beyond that, it can still be detected in the feces after there is no more proof of SARS-CoV-2 in the respiratory tract, leading to the suspicion that an oral-fecal infection route seems possible $[15,16]$.

\section{Differential Diagnosis}

Nevertheless, doctors treating COVID-19 patients showing GI symptoms - especially diarrhea and vomiting - should take common causes for this into account and test for noroviral and rotaviral infections as well as for bacterial infections (Campylobacter, Yersinia, Salmonella, Shigella, and Clostridium difficile).

\section{Treatment of GI Symptoms}

Doctors should treat these disorders symptomatically. First of all, fluid replacement represents the main therapeutical step. Diarrhea can be treated with loperamide (if there are no contraindications like bloody stool or fever) and antiemetics. The use of proton pump inhibitors is critical because their use during COVID-19 is associated with a worse outcome [17]. GI symptoms without involvement of the lungs represent no indication for treatment with dexamethasone or remdesivir.

\section{Pathophysiology of GI Symptoms in COVID-19}

That COVID-19 affects the intestinal system seems unsurprising when we consider that enterocytes express ACE2 more than other cells, tissues, or organs $[18,19]$. It might even be justified to assume that COVID-19 affects the respiratory system rather than the intestinal system because of the means of transmission and not because of the receptor density.

Lamers et al. [20] showed SARS-CoV-2 infections in gut organoids accompanied by upregulation of cytokine and interferon-related genes. Furthermore, soluble ACE2 blocks infection by SARS-CoV-2 by acting in the manner of a competitive agonist (Fig. 1).

\section{Inflammatory Bowel Disease and COVID-19}

Whether inflammatory bowel disease (IBD) patients have an increased risk of infection by SRAS-CoV-2 is controversial and most likely depends on the circumstances. A study from Wuhan with 204 patients with ulcerative colitis and 114 patients with Crohn's disease (CD) showed no SARS-CoV-2 infection in this cohort [20]. The reason is unclear, but it seems that infection control activities and awareness of the higher vulnerability for infections in combination with high hygiene standards were important in this regard. Whether therapy with biologicals or the diseases themselves provide protection from SARS-CoV-2 infection should be further investigated [3]. 
The low prevalence of COVID-19 is even more surprising due to the fact that ACE2 is highly expressed in patients with IBD [21, 22]. Garg et al. [23] showed that ACE2 activity and angiotensin appear in higher concentrations in IBD patients in comparison with healthy controls. In contrast, Patankar et al. [24] found that ACE2 but not TMPRSS2 expression is lower in the inflamed ilea of CD patients than in healthy controls. They studied different IBD mouse models and found that ACE2 but not TMPRSS2 was downregulated during inflammation. In summary, there are suggestions that IBD patients show a COVID-19 protection considering a reduced amount of ACE2 in inflamed mucosa in CD patients. However, further studies are needed for a better understanding of the complexity between IBD and COVID-19. Data from the Surveillance Epidemiology of Coronavirus under Research Exclusion for IBD (SECURE- IBD) showed an increased risk for severe COVID-19 in older patients, patients with comorbidities, and patients taking corticosteroids. Also, mesalamine and sulfasalazine, as well as the combination of TNF- $\alpha$ with thiopurines, showed a worse outcome for COVID-19. Anti-TNF- $\alpha$ antibodies, antiinterleukin-12 (IL-12)/IL-23 antibodies, and integrin antagonists seem to be safe in the context of COVID-19 [25, 26].

\section{IBD and Corticosteroids}

Corticosteroids can induce remission in IBD patients, and physicians use them often for a short time before the start of long-term treatment with a biological, for example. Due to their immunosuppressive properties, patients taking corticosteroids have an increased risk of gaining an infection. Even though dexamethasone showed promising results in treating COVID-19 [8], doctors must consider the different circumstances. Treatment of IBD with corticosteroids is not a prophylaxis for COVID-19 at the same time. Actually, the lowest possible corticosteroid dose should be used for treating IBD. Dexamethasone showed only positive effects in COVID-19 patients who received supplemental oxygen or invasive mechanical ventilation [8].

\section{IBD and TNF- $\alpha$ Blockade}

The use of anti-TNF- $\alpha$ antibodies is a widespread treatment concept for IBD $[27,28]$. Since they are associated with inhibition of antiviral immunity and can reactivate hepatitis $B$, there are concerns about their use in the COVID-19 pandemic [3]. However, the opposite could be true. In a study with 41 COVID-19 patients, Huang et al. [29] showed that TNF- $\alpha$ was elevated in patients treated in an intensive care unit (ICU) in comparison with non-ICU patients. Thus, there is a possible protective effect of TNF- $\alpha$ antibodies in COVID-19. Abdullah et al. [30] reported an 18-year-old ulcerative colitis patient who developed COVID-19 four days after infliximab application. She only developed mild symptoms and there was no need for hospitalization. Additionally, sepsis patients with hyperinflammation and high IL-6 levels may benefit from TNF- $\alpha$ inhibition [3].

\section{IBD and Integrin Receptor Antagonists}

Vedolizumab, an $\alpha 4 / \beta 7$ antibody, inhibits the homing of T helper (Th) 1, Th2, Th9, Th17, and regulatory T cells to the inflamed intestine by blocking integrin attaching to mucosal vascular addressin cell adhesion molecule 1 (MAdCAM-1), thereby ameliorating intestinal inflammation [31-35]. Its use seems safe since reactivation of hepatitis B has not occurred yet using vedolizumab [36].

\section{IBD and p40 Blockade}

Ustekinumab is an anti-p40 antibody that blocks IL-12 and IL-23 [37, 38]. Since there have been no increased viral infections during ustekinumab therapy, its use during the COVID-19 pandemic seems to be safe [3].

\section{$I B D$ and JAK Inhibition}

The inhibition of Janus kinases is a new approach for treating IBD $[3,39]$. Inhibition of JAK2 (Janus kinase 2) impairs viral entry and the Th17-related cytokine storm. Clinical trials using JAK inhibitors for treating COVID-19 are ongoing $[3,40]$. For example, a study investigating the use of baricitinib in COVID-19 is currently running (NCT04421027).

\section{COVID-19 and Liver Damage}

Overall, 20-30\% of COVID-19 patients present with elevated liver enzymes [41]. Fan et al. [42] even found that $50.7 \%$ of COVID-19 patients showed abnormal liver functions in a study involving 148 patients. It is important to be aware that ACE2 is highly expressed in bile duct cells and sparsely in hepatocytes [43]. Cai et al. [44] showed that $76.3 \%$ of COVID-19 patients present with liver injury and $21.5 \%$ show liver damage in a study with 417 patients. A study by Chen et al. [45] involving $502 \mathrm{COV}$ ID-19 patients revealed that liver abnormalities represent an indicator of severe disease, including higher rates of systemic inflammatory response syndrome and death.

The reasons for abnormal liver enzymes can be related to different causes. As described above, cholangiocytes and hepatocytes express ACE2, so SARS-CoV-2 can harm the liver directly (Fig. 2). Other reasons could be drug related (e.g., acetaminophen, remdesivir) and hypoxia caused by pneumonia or hyperinflammation [41]. Since many patients with COVID-19 have their first contact with the health system for a longer time, liver enzymes could have been elevated because of different circum- 




Fig. 2. The S spike of SARS-CoV-2 is activated through proteolytic cleavage by TRMPSS 2 and can connect with ACE2 on bile duct cells and hepatocytes. Note that bile duct cells highly express ACE2, while hepatocytes express it less. Created with Biorender. com.

stances (heavy alcohol consumption during social distancing) [46].

\section{COVID-19 and Underlying Liver Diseases}

Li et al. [47] presented a case series of 7 patients with chronic hepatitis B and COVID-19. They could not detect any worse outcomes in these patients in comparison with matched patients. Of course, this study had limitations regarding the small number of patients. Furthermore, the manuscript offered no information regarding whether the patients had received hepatitis B therapy.

Whether or not patients with an underlying liver disease show heavier disease courses has been unclear for a long time. However, register studies reveal that this patient group has a higher risk for severe COVID-19 infections [11] and an increased risk of death. Strikingly, this correlates with the extent of the pre-existing liver damage. Vice vera, COVID-19 can lead to decompensation of a pre-existing liver damage, so some guidelines recommend testing for COVID-19 in decompensating liver cirrhosis without any other signs of COVID-19-like respiratory symptoms. Beyond that, distinguishing whether the higher rate of death in liver patients with COVID-19 is because of the underlying liver disease or different relevant comorbidities is challenging [14, 48-50].

\section{Patients after Liver Transplantation}

Pereira et al. [51] presented a study with 90 solid organ recipients, 13 of whom had received a new liver. The patients had a higher risk for a severe disease and a higher mortality. Notably, $31 \%$ of the patients presented with diarrhea and 7 patients initially had negative test results for SARS-CoV-2.

In contrast, Webb et al. [52] published a study with 151 patients who received LTX. In this study, after LTX patients had no higher risk for a severe disease course. LTX was not an independent risk factor for death, but age and comorbidities were. Colmenero and al. [53] showed similar results. In their study with 111 LTX patients, COVID-19 had a greater incidence in LTX patients but a lower mortality rate. Still, we have to take into account that these patients are highly immunosuppressed. There are recommendations to reduce immunosuppressive medications in LTX patients with COVID-19, especially when they show lymphopenia or disease worsening, yet there is a lack of evidence to support this [14]. Colmenero et al. [53] propose that a withdrawal of immunosuppressant agents may not be necessary. On the other hand, they report that in contrast to calcineurin inhibitors and everolimus, mycophenolate increases the risk for a severe COVID-19 course in a dose-dependent manner.

\section{COVID-19 and Pancreatic Disease}

Even though the ACE2 receptor and TMPRSS2 are expressed on pancreatic ductular cells, the pancreas itself is rarely affected by COVID-19 [14]. Inamdar et al. [54] performed a retrospective study and found that only $0.27 \%$ of patients presenting with COVID-19 had an acute pancreatitis. The opposite seems more likely: patients with severe COVID-19 develop an acute pancreatitis. Dirweesh et al. [55] presented a retrospective analysis with 339 patients who suffered from an acute pancreatitis; $22 \%$ of them had a positive SARS-CoV-2 polymerase chain reaction test and $18.7 \%$ had COVID-19. Alcohol-induced and idiopathic acute pancreatitis dominated the cause for acute pancreatitis in SARS-CoV-2-positive and negative patients. However, patients with COVID-19 presented a higher incidence of multiorgan failure and mortality. Even though it remains speculative, it seems that hyperinflammation and systemic disease lead to a severe course in COVID-19 patients with acute pancreatitis. Camostat mesylate is used for treatment of acute pancreatitis in Japan and inhibits TMPRSS2, preventing SARS-CoV-2 infection in the lungs. A clinical trial for the use of camostat mesylate is currently in progress (NCT04353284).

\section{COVID-19 and GI Malignancies}

Due to their malignant disease and therapy, patients with GI cancers are immunosuppressed and have a 2 -fold higher risk of developing COVID-19 [56]. Treating these 
Table 1. Registers for GI patients with COVID-19

\begin{tabular}{lll}
\hline Database & Disease & Link \\
\hline SECURE-IBD & IBD (microscopic colitis, ulcerative colitis) & https://covidibd.org \\
SECURE-EOE/EGID & Eosinophilic gastrointestinal disease & https://eureos.online/newsreader-2102/secure-eoe-egid-registry.html \\
SECURE-Celiac Disease & Celiac diseases & https://covidceliac.org \\
\hline
\end{tabular}

patients is challenging. The most important measures are social distancing, wearing a mask, and hand disinfection.

\section{Conclusion}

Even though COVID-19 patients present most often with fever, pneumonia, and upper respiratory symptoms, many develop GI disorders. These may even appear before other symptoms, or they can even appear to be the only symptom. Physicians must be aware of this and consider COVID-19 in patients with GI symptoms. They should also be a warning signal for doctors treating COVID-19 patients, for they correlate with a worse outcome. Table 1 presents registers for patients with an underlying GI disorder and COVID-19.

Currently, we have two approved drugs for treating COVID-19. Dexamethasone and remdesivir showed benefits for COVID-19 patients with need for oxygen supplementation or mechanical ventilation [6-8]. There was no benefit for patients with normal respiratory features.

Since acute respiratory distress syndrome and sepsis are the main leading causes for COVID-19-related death, it is understandable to focus therapy on the respiratory tract. However, the more we know about COVID-19 the more we see its complexity. COVID-19 is a systemic disease that affects all kinds of organs. The GI tract is one of the most common body parts to suffer from COVID-19.

Loss of appetite, diarrhea, nausea, and vomiting are common disorders in COVID-19. Elevated liver enzymes can be seen on a regular basis, but liver damage can also follow SARS-CoV-2 infection. Involvement of the pancreas is rare but is also a warning sign.

The aim of this review was to present the current knowledge (and questions) we have about GI involvement in COVID-19. Especially our knowledge about IBD and COVID-19 has to improve [3] since here we can observe the interplay between the different cytokines, hopefully resulting in both a better understanding of IBD and COVID-19. After 1 year of experience with this disease and the intensive research that has been conducted, we are slowly beginning to better understand its nature. Still, many questions remain to be answered and there is much research to be done.

\section{Conflict of Interest Statement}

A.J. received speaker fees from AbbVie, MSD, Eisai, and Roche; travel grants from Servier, BMS, Amgen, and Lilly, sponsoring from Lilly, Cellgene, and Amgen, and personal fees from Servier and Amgen. M.F.N. declares personal fees from Boehringer and Abbvie, Roche and Takeda, and J\&J.

\section{Funding Sources}

M.F.N. was supported by the German Research Foundation (DFG) within the SPP1656 and TRR241 (C04).

\section{Author Contributions}

A.J. and M.F.N. wrote the original draft and performed the review and editing of the manuscript.

\section{References}

1 Wu F, Zhao S, Yu B, Chen YM, Wang W, Song ZG, et al. A new coronavirus associated with human respiratory disease in China. $\mathrm{Na}$ ture. 2020 Mar;579(7798):265-9.

2 Dong E, Du H, Gardner L. An interactive web-based dashboard to track COVID-19 in real time. Lancet Infect Dis. 2020 May;20(5): 533-4.

3 Neurath MF. COVID-19 and immunomodulation in IBD. Gut. 2020 Jul;69(7):1335-42.
4 Hoffmann M, Kleine-Weber H, Schroeder S, Krüger N, Herrler T, Erichsen S, et al. SARSCoV-2 cell entry depends on ACE2 and TMPRSS2 and is blocked by a clinically proven protease inhibitor. Cell. 2020 Apr;181(2): 271-280.e8.

5 Schett G, Sticherling M, Neurath MF. COVID-19: risk for cytokine targeting in chronic inflammatory diseases? Nat Rev Immunol. 2020 May;20(5):271-2.
6 Beigel JH, Tomashek KM, Dodd LE, Mehta AK, Zingman BS, Kalil AC, et al.; ACTT-1 Study Group Members. Remdesivir for the Treatment of Covid-19 - Final Report. N Engl J Med. 2020 Oct;383(19):1813-26.

7 Goldman JD, Lye DC, Hui DS, Marks KM, Bruno R, Montejano R, et al.; GS-US-540-5773 Investigators. Remdesivir for 5 or 10 Days in Patients with Severe Covid-19. N Engl J Med. 2020 May;383(19):1827-37. 
8 Hanauer SB, Feagan BG, Lichtenstein GR, Mayer LF, Schreiber S, Colombel JF, et al. Dexamethasone in Hospitalized Patients with Covid-19 - Preliminary Report. N Engl J Med. 2020 Jul 17;359(9317):NEJMoa2021436.

9 Leppkes M, Knopf J, Naschberger E, Lindemann A, Singh J, Herrmann I, et al. Vascular occlusion by neutrophil extracellular traps in COVID-19. EBioMedicine. 2020 Aug; 58: 102925.

10 Redd WD, Zhou JC, Hathorn KE, Mccarty TR, Bazarbashi AN, Thompson CC, et al. Prevalence and characteristics of gastrointestinal symptoms in patients with severe acute respiratory syndrome coronavirus 2 infection in the United States: a multicenter cohort study. Gastroenterology. 2020;159(2):765-7. e2..

11 Konturek PC, Harsch IA, Neurath MF, Zopf Y. COVID-19- more than respiratory disease: a gastroenterologist's perspective. J Physiol Pharmacol. 2020 Apr;71(2):765-767.e2.

12 Pan L, Mu M, Yang P, Sun Y, Wang R, Yan J, et al. Clinical Characteristics of COVID-19 Patients With Digestive Symptoms in Hubei, China: A Descriptive, Cross-Sectional, Multicenter Study. Am J Gastroenterol. 2020 May; 115(5):766-73.

13 Stokes EK, Zambrano LD, Anderson KN, Marder EP, Raz KM, El Burai Felix S, et al. Coronavirus Disease 2019 Case Surveillance - United States, January 22-May 30, 2020. MMWR Morb Mortal Wkly Rep. 2020 Jun; 69(24):759-65.

14 Hunt RH, East JE, Lanas A, Malfertheiner P, Satsangi J, Scarpignato C, et al. COVID-19 and gastrointestinal disease. Implications for the gastroenterologist. Dig Dis. 2020. doi: 10.1159/000512152.

15 Tian Y, Rong L, Nian W, He Y. Review article: gastrointestinal features in COVID-19 and the possibility of faecal transmission. Aliment Pharmacol Ther. 2020 May;51(9):843-51.

16 Ling Y, Xu SB, Lin YX, Tian D, Zhu ZQ, Dai $\mathrm{FH}$, et al. Persistence and clearance of viral RNA in 2019 novel coronavirus disease rehabilitation patients. Chin Med J. 2020 May; 133(9):1039-43.

17 Lee SW, Ha EK, Yeniova AÖ, Moon SY, Kim SY, Koh HY, et al. Severe clinical outcomes of COVID-19 associated with proton pump inhibitors: a nationwide cohort study with propensity score matching. Gut. 2020;gutjnl2020-322248.

18 Qi F, Qian S, Zhang S, Zhang Z. Single cell RNA sequencing of 13 human tissues identify cell types and receptors of human coronaviruses Biochem Biophys Res Commun. 2020 May;526(1):135-40.

19 Lamers MM, Beumer J, van der Vaart J, Knoops K, Puschhof J, Breugem TI, et al. SARS-CoV-2 productively infects human gut enterocytes. Science. 2020 Jul 3;369(6499): $50-4$

20 An P, Ji M, Ren H, Su J, Kang J, Yin A, et al. Protection of 318 inflammatory bowel disease patients from the outbreak and rapid spread of COVID-19 infection in Wuhan, China. SSRN Electron J. 2020. doi: 10.2139/ssrn. 3543590 .
21 Garg M, Royce SG, Tikellis C, Shallue C, Batu $\mathrm{D}$, Velkoska E, et al. Imbalance of the reninangiotensin system may contribute to inflammation and fibrosis in IBD: a novel therapeutic target? [Internet]. Gut. 2020 May;69(5): 841-51. Available from: https://gut.bmj.com/ lookup/doi/10.1136/gutjnl-2019-318512

22 Harmer D, Gilbert M, Borman R, Clark KL. Quantitative mRNA expression profiling of ACE 2, a novel homologue of angiotensin converting enzyme. FEBS Lett. 2002 Dec; 532(1-2):107-10.

23 Garg M, Burrell LM, Velkoska E, Griggs K, Angus PW, Gibson PR, et al. Upregulation of circulating components of the alternative renin-angiotensin system in inflammatory bowel disease: A pilot study [Internet]. J Renin Angiotensin Aldosterone Syst. 2015 Sep; 16(3):559-69. Available from: http://journals.sagepub.com/doi/10.1177/ 1470320314521086

24 Patankar JV, Chiriac M, Lehmann M, Kühl AA, Atreya R, Becker C. The SARS-CoV-2 attachment receptor ACE2 is decreased in Crohn's disease and regulated by microbial and inflammatory signaling. Gastroenterology. 2020. doi: 10.1053/j.gastro.2020.10.021

25 Ungaro RC, Brenner EJ, Gearry RB, Kaplan GG, Kissous-Hunt M, Lewis JD, et al. Effect of IBD medications on COVID-19 outcomes: results from an international registry. Gut. 2020. doi: 10.1136/gutjnl-2020-322539.

26 Brenner EJ, Ungaro RC, Gearry RB, Kaplan GG, Kissous-Hunt M, Lewis JD, et al. Corticosteroids, But Not TNF Antagonists, Are Associated With Adverse COVID-19 Outcomes in Patients With Inflammatory Bowel Diseases: Results From an International Registry. Gastroenterology. 2020 Aug;159(2):481-491. e3.

27 Hanauer SB, Feagan BG, Lichtenstein GR, Mayer LF, Schreiber S, Colombel JF, et al.; ACCENT I Study Group. Maintenance infliximab for Crohn's disease: the ACCENT I randomised trial. Lancet. 2002 May;359(9317): 1541-9.

28 Rutgeerts P, Sandborn WJ, Feagan BG, Reinisch W, Olson A, Johanns J, et al. Infliximab for induction and maintenance therapy for ulcerative colitis. N Engl J Med. 2005 Dec; 353(23):2462-76.

29 Huang C, Wang Y, Li X, Ren L, Zhao J, Hu Y, et al. Clinical features of patients infected with 2019 novel coronavirus in Wuhan, China. Lancet. 2020 Feb;395(10223):497-506

30 Abdullah A, Neurath MF, Atreya R. Mild COVID-19 Symptoms in an Infliximab-Treated Ulcerative Colitis Patient: Can Ongoing AntiTNF Therapy Protect against the Viral Hyperinflammatory Response and Avoid Aggravated Outcomes? Visc Med. 2020 Aug;36(4): 338-42.

31 Balzola F, Cullen G, Ho GT, Russell R. Vedolizumab as induction and maintenance therapy for Crohn's disease [Commentary]. Inflamm Bowel Dis Monit. 2014;14(2):55-6.

32 Feagan BG, Rutgeerts P, Sands BE, Hanauer S, Colombel JF, Sandborn WJ, et al.; GEMINI 1 Study Group. Vedolizumab as induction and maintenance therapy for ulcerative colitis. N Engl J Med. 2013 Aug;369(8):699-710.
33 Sands BE, Peyrin-Biroulet L, Loftus EV Jr, Danese S, Colombel JF, Törüner $\mathrm{M}$, et al.; VARSITY Study Group. Vedolizumab versus adalimumab for moderate-to-severe ulcerative colitis. N Engl J Med. 2019 Sep;381(13): 1215-26.

34 Fischer A, Zundler S, Atreya R, Rath T, Voskens C, Hirschmann S, et al. Differential effects of $\alpha 4 \beta 7$ and GPR15 on homing of effector and regulatory $\mathrm{T}$ cells from patients with UC to the inflamed gut in vivo. Gut. 2016 Oct; 65(10):1642-64.

35 Zundler S, Fischer A, Schillinger D, Binder MT, Atreya R, Rath T, et al. The $\alpha 4 \beta 1$ homing pathway is essential for ileal homing of Crohn's disease effector T cells in vivo. Inflamm Bowel Dis. 2017 Mar;23(3):379-91.

$36 \mathrm{Ng}$ SC, Hilmi IN, Blake A, Bhayat F, Adsul S, Khan QR, et al. Low frequency of opportunistic infections in patients receiving vedolizum$\mathrm{ab}$ in clinical trials and post-marketing setting. Inflamm Bowel Dis. 2018 Oct;24(11): 2431-41.

37 Sands BE, Sandborn WJ, Panaccione R, O'Brien CD, Zhang H, Johanns J, et al.; UNIFI Study Group. Ustekinumab as Induction and Maintenance Therapy for Ulcerative Colitis. N Engl J Med. 2019 Sep;381(13): 1201-14.

38 Feagan BG, Sandborn WJ, Gasink C, Jacobstein D, Lang Y, Friedman JR, et al.; UNITIIM-UNITI Study Group. Ustekinumab as Induction and Maintenance Therapy for Crohn's Disease. N Engl J Med. 2016 Nov; 375(20):1946-60.

39 Gerlach K, Lechner K, Popp V, Offensperger $\mathrm{L}$, Zundler S, Wiendl M, et al. The JAK1/3 inhibitor to tofacitinib suppresses T cell homing and activation in chronic intestinal inflammation. J Crohns Colitis. 2020 Aug. doi: 10.1093/ecco-jcc/jjaa162.

40 Rodriguez-Garcia JL, Sanchez-Nievas G, Arevalo-Serrano J, Garcia-Gomez C, Jimenez-Vizuete JM, Martinez-Alfaro E. Baricitinib improves respiratory function in patients treated with corticosteroids for SARS-CoV-2 pneumonia: an observational cohort study. Rheumatology. 2020. doi: 10.1093/rheumatology/ keaa587.

41 Patel KP, Patel PA, Vunnam RR, Hewlett AT, Jain R, Jing R, et al. Gastrointestinal, hepatobiliary, and pancreatic manifestations of COVID-19. J Clin Virol. 2020 Jul;128:104386.

42 Fan Z, Chen L, Li J, Cheng X, Yang J, Tian C, et al. Clinical features of COVID-19-related liver functional abnormality. Clin Gastroenterol Hepatol. 2020 Jun;18(7):1561-6.

43 Mohandas S, Vairappan B. SARS-CoV-2 infection and the gut-liver axis. J Dig Dis. 2020. doi: 10.1111/1751-2980.12951.

44 Cai Q, Huang D, Yu H, Zhu Z, Xia Z, Su Y, et al. COVID-19: abnormal liver function tests. J Hepatol. 2020 Sep;73(3):566-74.

45 Chen LY, Chu HK, Bai T, Tu SJ, Wei Y, Li ZL, et al. Liver damage at admission is an independent prognostic factor for COVID-19 [Internet]. J Dig Dis. 2020 Sep;21(9):512-8. Available from: https://onlinelibrary.wiley. com/doi/10.1111/1751-2980.12925

46 Chick J. Alcohol and COVID-19. Alcohol Alcohol. 2020 Jun;55(4):341-2. 
47 Li Y, Li C, Wang J, Zhu C, Zhu L, Ji F, et al. A case series of COVID-19 patients with chronic hepatitis B virus infection. J Med Virol. 2020;21:2-7.

48 Iavarone M, D’Ambrosio R, Soria A, Triolo M, Pugliese N, Del Poggio P, et al. High rates of 30-day mortality in patients with cirrhosis and COVID-19. J Hepatol. 2020 Nov;73(5): 1063-71.

49 Marjot T, Moon AM, Cook JA, Abd-Elsalam S, Aloman C, Armstrong MJ, et al. Outcomes following SARS-CoV-2 infection in patients with chronic liver disease: an international registry study. J Hepatol. 2020. doi: 10.1016/j. jhep.2020.09.024.

50 Moon AM, Webb GJ, Aloman C, Armstrong MJ, Cargill T, Dhanasekaran R, et al. High mortality rates for SARS-CoV-2 infection in patients with pre-existing chronic liver disease and cirrhosis: preliminary results from an international registry. J Hepatol. 2020 Sep; 73(3):705-8.
51 Pereira MR, Mohan S, Cohen DJ, Husain SA, Dube GK, Ratner LE, et al. COVID-19 in solid organ transplant recipients: initial report from the US epicenter. Am J Transplant. 2020 Jul;20(7):1800-8.

52 Webb GJ, Marjot T, Cook JA, Aloman C, Armstrong MJ, Brenner EJ, et al. Outcomes following SARS-CoV-2 infection in liver transplant recipients: an international registry study. Lancet Gastroenterol Hepatol. 2020 Nov;5(11):1008-16.

53 Colmenero J, Rodríguez-Perálvarez M, Salcedo M, Arias-Milla A, Muñoz-Serrano A, Graus J, et al. Epidemiological pattern, incidence and outcomes of COVID-19 in liver transplant patients. J Hepatol. 2020. doi: 10.1016/j.jhep.2020.07.040.
54 Inamdar S, Benias PC, Liu Y, Sejpal DV, Satapathy SK, Trindade AJ; Northwell COVID-19 Research Consortium. Prevalence, risk factors, and outcomes of hospitalized patients with COVID-19 presenting as acute pancreatitis. Gastroenterology. 2020. doi: 10.1053/j. gastro.2020.08.044.

55 Dirweesh A, Li Y, Trikudanathan G, Mallery JS, Freeman ML, Amateau SK. Clinical outcomes of acute pancreatitis in patients with coronavirus disease 2019. Gastroenterology. 2020 Nov;159(5):1972-4.

56 Al-Shamsi HO, Alhazzani W, Alhuraiji A, Coomes EA, Chemaly RF, Almuhanna M, et al. A practical approach to the management of cancer patients during the novel coronavirus disease 2019 (COVID-19) pandemic: an international collaborative group. Oncologist. 2020 Jun;25(6):e936-45. 